\title{
The Journalistic Discourse Translating Strategies: From English into Arab
}

\author{
Houaria $\mathrm{CHAAL}^{1}$ \\ ${ }^{1}$ Dr., Department of English, Chlef University, Algeria \\ Correspondence: Dr. Houaria CHAAL, Department of English, Chlef University, Algeria.
}

Received: March 26, 2019

Accepted: May 5, 2019 Online Published: May 9, 2019

doi:10.5430/wjel.v9n2p19

URL: https://doi.org/10.5430/wjel.v9n2p19

\begin{abstract}
The journalistic discourse is a communicative act of particular linguistic phenomenon that requires some special norms and reflects on social, cultural, political, ideological aspects.Thus, it is regarded as a specialized discourse, and its translation imposes a real challenge for the translator. In this regard, this paper examines the journalistic discourse translation with a more focus on the transfer strategies. News translation, in fact, might be risky when it relies on the media authority that should be respected. Moreover, it is often politically oriented. Accordingly, the current paper aims at discovering whether good transfer is appropriately assured by news translating or news making. For this purpose, a comparative analysis of the source and target press articles (English- Arabic) has been conducted based on the use of a range of micro translation strategies for news discourses. The study showed that good transfer is better assured by trans-editing and reproduction among other appropriate strategies of news translation required for the journalistic discourse.
\end{abstract}

Keywords: journalistic discourse, news translation, translation strategies, reproduction, transediting

\section{Introduction}

Media and translation have become inseparable disciplines in this globalized world where they play an indispensable role in the international transmission of news. Not only they inform the reader, but they also facilitate the flow of information. Therefore, translators are required for any media institution, for instance the global news agencies, for efficient communication. However, media translation has rather been neglected by Translation Studies. News translation is quite recent. Nevertheless, it is performed by newspapers in different countries. Because of translation, press reaches a very large number of readers and translated news contributes to the shaping of readers' opinions, actively influencing the way they perceive the world around them. Moreover, if we bear in mind the range of topics and events that newspapers and magazines publish, it is indeed a challenging task for a real translator since the journalistic discourse is a particular linguistic phenomenon that implies some special norms and reflects on different aspects such as; social, cultural, political, and ideological ones. Journalists write news stories with a given structure, order, viewpoint and values that should be transferred into another language.

\section{The Journalistic Discourse Definition and Features}

Language is a powerful social phenomenon. It is used to express our feelings, thoughts, ideas and experiences. The social and cultural context, from which language emanates, gives the discursive power to language. Therefore, language and discourse are closely-related in that "language provides names for categories, and so helps to set their boundaries and relationships, and discourse allows these names to be spoken and written frequently, so contributing to the apparent reality and currency of the categories." (Fowler 1991: 94) In this sense, discourse is an instrument that enables and adds to the representation of linguistic categories. Discourse is produced through the structures of language yet is never limited to linguistic tools. As Van Dijk (1988: 2) puts forth, "discourse is an intricate event built through a social context with its participants and their production and reception processes. "

Since genre is «a specific dynamic model of structural and language organisation of some communication texts composed by extra-linguistic factors of communication. » (Arutjunova 1990: 48), discourse and genre have a very close relationship. Social occasions are embedded in genres, and as a result of historical processes, genres are inscribed in the conventions of a society. (Hatim and Mason, 1990: 73)

Hence, the genre of news reports has its own discourse created by institutions. Each genre forms its discourse 
structure which is realized in texts. This genre reflects events happening in the world; therefore, social and political knowledge and beliefs are gained through these reports. (Van Dijk, 1991, p.110)

For these overlapped concepts, the journalistic discourse is a particular and complex communicative act which embraces the social context. In fact, media texts not only mirror reality but also construct its versions. They determine the societal reality, public and political aspects of human lives, economic, moral, artistic, scientific and spiritual issues. In this regard, Los (2008: 25) argues that "journalism is a social science and human study ". It is often called the "language of media" or "discourse of mass media." (Bell, 1995)

News reports are mainly written to inform the public about world affairs. These reports should be up-to-date to provide readers with precise information. Thus, they are both produced and consumed quickly. Apart from hot political and economic agenda of the world, news reports cover a variety of themes. Other subjects such as science, magazine, sports, health, and technology, all of which form a part of the social world, comprise a remarkable amount of news coverage. Each of these sections in a newspaper or on the website of a news outlet represents a genre. As Fowler (1991: 227) mentions, “(...) there exist within newspapers distinct genres of writing: editorials, reviews, financial reports, sports, accounts of parliamentary proceedings, etc. Presumably, each genre employs certain textual strategies which cue readers to expect a particular kind of discursive experience, a particular view on some specialized portion of the represented world."

News reports pass through a series of production processes contributed by journalists, reporters, correspondents, editors, translators, and chief editors before they reach readers. All these agents have to comply with the regulations and policies adopted by their institutions. From the very beginning of the process, namely the collection of news stories, to the last stage of publishing news, the aforementioned agents make decisions in line with the organizational constraints. Thus, news reports rarely reach the audience in their original forms; they go through transformation.

News is not produced in a vacuum, rather in a social context that has its own structures and agents. Producers of news texts consider the shared knowledge and values of the institution as well as the society in which they operate. As a result of institutional news formation processes, a target readership is created, which then becomes participants of the context in which news is produced and consumed.

\section{The Journalistic Discourse Structure}

Journalistic discourse differs from the other types of texts in terms of content and form. News stories are formed of various parts. There is a hierarchy in the structure of news.And the most important information is located in the first place and is followed by details supporting the main focus of events. The news schema outlined by van Dijk (1988) is comprised of "headline and lead (together form the summary), main events, context and history (together form the background), verbal reactions, and comments".

Headline and lead together precede the other information in a news text; thus, it could be stated that they contain the most outstanding information of the text. Headlines summarize the news events as well as serve the purpose of drawing readers' attention (Bell 1991: 189-90, cited in Valdéon 2007: 157). There is a main headline and a subheadline leads generally appear in separately printed bold characters, and main events are the part where the relevant details of the news story are presented and evaluated. Main events are generally followed by context and history. As Van Dijk (1988: 54) argues, context denotes "the actual situation, consisting of other concrete news events, and not a general structural situation." Whereas context is generally the main event of the previous related news report; the background part, including context as well as history, is more comprehensive; hence, it could be said that background has also a historical dimension. For Van Dijk (Ibid), history is "the section of a news text that deals with non-recent past history of actual situations and their events." While verbal reactions could be defined as the ideas put forth by prominent figures. Comments are generally remarks and evaluations of journalists or newspapers as institutions (van Dijk 1988: 56)

Leon V. Sigal said, "News is not what happens, but what someone says has happened or will happen. "Readers may interpret such Leon's statement differently: we may understand that the news is made and constructed. Therefore, news stories are structured through various transformative procedures. Space and time constraints as well as institutional policies force producers of news texts to alter stories before publishing them. Allan Bell (1991) mentions three types of media text transformations: information deletions, lexical substitutions, and syntactic editing rules (cited in Valdéon 2007: 101). According to Bell (1991), editors delete certain sections parts of a news story, add explanation where necessary, and revise stylistic problems in order to produce precise and newsworthy stories. (cited in Kuo and Nakamura 2005: 399) On the other hand, Van Dijk speaks of a broader category oftransformative practices. These include "selection, reproduction, summarisation, local transformation (addition, deletion, 
permutation, and substitution), stylistic and rhetorical formulation". Van Dijk (1988: 118) states also that stylistic formulation is the most effective way of reflecting the institutional values in news texts, and rhetorical reformulation enables producers of news texts to " $a$ story more effective by the use of understatements or exaggerations, comparisons, and suggestive metaphors". Transformations during the production of news texts are made in accordance with the models of producers of news texts who have to comply with the discourse of the institution where they work; thus, transformations "must involve subjective or group-based (...) norms and values."(Van Dijk 1988: 118)

\section{News Translation}

Practices in news translation are very much determined by the expectations of the target readers and time constraints. The main goal in news production and translation is to provide readers with the most up-to-date information without making any concessions to truthfulness in the content of news items. While doing that, much importance should be given to the expectations of the readers from different communities.

According to Bassnett, reshaping news stories for another community requires 'acculturation', which carries a text to target readers without any knowledge of any other system (p. 120). During this process, various transformational strategies such as addition, omission and summarization are adopted to meet cultural conventions of target readers. Bassnett argues such transformations are vital in the process of news translation, and thus, it is almost meaningless to talk about the freedom of the translator (p. 125)

News translation has a different nature which is much debated in the realm of translation studies. Some researchers have even made efforts to find a name for this area of translation. Karen Stetting (1989) coined a new term, 'transediting' which has gained acceptance in some circles. While introducing the new term, Stetting (1989) emphasizes the expectations of the target text addressees which necessitate cultural adaptations in news texts (cited in Schäffner 2012: 867). Furthermore, according to Stetting (1989), the expectations as well as the needs of the target text addressees are based on the function fulfilled by the target text (cited in Schäffner 2012: 869). However, Schäffner argues that this new term coined by Stetting and her efforts to legitimize it conform to the arguments in functionalist approaches to translation studies (p. 869). She states both functionalist approaches and news translation put special emphasis on the expectations of target receivers, which are guided by the function of the target text. Moreover, the greater freedom attributed to the trans-editor by Stetting is suitable to 'professional expertise' proposed by Holz-Mänttäri, who legitimizes interventions on the part of the translator (p. 869). However, Bielsa and Bassnett (2009: 2) state, “information that passes between cultures through news agencies is not only 'translated' in the interlingual sense, it is reshaped, edited, synthesized and transformed for the consumption of a new set of readers".

Therefore, news translation processes are very complex. Schäffner (2012: 874) emphasizes that language change is fused and integrated in such processes; and thus, news agencies regard translation as one of the journalistic tasks. She also discusses that avoiding the use of the term 'translation' due to the intense transformational processes in news translation reduces this term to "a more narrow understanding of translation as literal translation" (p. 875). She further suggests such transformations occur not only in news translation but also in other areas such as; subtitling or screen translation (Schäffner: 876). She views micro- and macro-levelshifts as "an integral part of any translation process", and stresses that newstranslation, like any other form of translation, is "a textual and a sociocultural process which involves transformations' (Ibid: 881)

Translators mostly have to comply with some norms imposed on them either by the societies or by the institutions in which they work. They have to produce their texts inline with the power relations, dominant ideologies, or economic conditions surrounding them. Therefore, they usually have to deviate from the standard text production norms and make conscious decisions to adapt to the needs of target readers, the institutions, or the societies in general. To this end, Tymoczko and Gentzler (2002) state that, "Translation thus is not simply an act of faithful reproduction but, rather, a deliberateand conscious act of selection, assemblage, structuration, and fabrication - and even, insome cases, of falsification, refusal of information, counterfeiting, and the creation ofsecret codes. In these ways translators, as much as creative writers and politicians, participate in the powerful acts that create knowledge and shape culture. "( $p$. xxi)

When all these practices are taken into account, translators need to make shifts at various levels in texts such as adding explanatory details or deleting irrelevant parts. These two shifts are mostly practiced in news translation to meet the needs of localcultures.

Translation, assuming a significant role in localizing news products not only highlights cultural elements but also 
contributes to globalization by enabling more and more target readers to reach global events. In this sense, translation is "an analytic borderland where the global and the local are articulated." (Bielsa and Bassnett: 28)

Although the dominant strategy in news translation is domestication, there are also instances of foreignization strategies, especially in the dissemination of the political discourse where ideological constraints are more apparent. Such instances are rare opportunities which make translational practices visible in global news, which in turn contributes to a better understanding of the status of translation in cultural globalization (Ibid). Cultural globalization necessitates translation in many areas since today's lingua franca of the world is English; however, translation also feeds cultural globalization through its role of homogenizing cultural elements between different communities.

For these reasons, news translation seems as mediation, rewriting, and functional translation.

\subsection{Strategies for News Translation}

The area of news translation has its own main features which have common as well as differing points with the other areas of translation. Cultural and ideologicalconstraints, norms and values of target readers as well as institutional discoursepractices are the decisive aspects in all translation processes. However, in news translation, these constraints are more conspicuous due to the nature of journalisticpractices. Globalization of media outlets also contributes to this complicated process; thus, requirements of globalization, journalism, and translation all overlap at the sametime. For instance, globalization requires a standardization of news websites.

Journalistic practices have their own purposes such as communicating rightful news to readers as quickly as possible. In the case of foreign news, journalistic practices need to ensure the comprehensibility of the news on the part of the readers. At this stage, the crucial responsibility falls on the translator/editor. Hence, the translator/editor should take translational and journalistic as well as institutional discourse requirements into account.

Thus, in order to ensure an efficient translation, some strategies are suggested.

\subsubsection{Macro Strategies}

Venuti (1995) proposes two types of translation strategies: foreignization and domestication. While foreignization retains the "foreign" features of the source text,domestication helps to reproduce the source text author's "intended meaning in an idiomatic and natural style appropriate to the TL"(Xiaojua, 2010: 136). In newstranslation, material needs to be altered and adapted to the needs of the target culture, since comprehension of news stories on the part of the target reader is the priority. Thus," the dominant strategy is absolute domestication." (Bielsa and Bassnett, 2009: 10).

Although Venuti (1995: 17) claims domestication in translation is an insidious process which 'decreases the cultural capital of foreign values', it minimizes foreignness fortarget readers, which is necessary in the context of news translation. Venuti (1995:20) favors foreignization, discussing that it"registers the linguistic and cultural difference of the foreign text, sending the reader abroad. "Yet on the other hand, he admits that domestication creates fluent translation (p. 78). Foreignization enables information and values of one culture to "be transmitted to another without losing its original meaning”, and it helps to enrich expressions in languages by'absorbing fresh elements' from different language systems (Yin, 2012: 63). On the other hand, foreignization may obscure the meaning due to alien cultural images and impair 'the norm of the target language (ibid., p. 63). On the contrary, domestication reduces the difficulty in reading and understanding texts. According to Shuttleworth and Cowie (1997: 59), "domestication designates the type of translation in which a transparent, fluent style is adopted to minimize the strangeness of the foreign text for target language readers." In the transfer of foreign news, different textual practices such as addition, omission, clarification, paraphrasing take place, which result in "reshaping in accordance with target culture conventions' and 'rewriting in a particular house style."

In the sense of Venuti (1995: 20), domestication may refer to 'an ethnocentric reduction of the foreign text to target-language cultural values, yet as Bassnett (2005: 127) discusses, in the field of news reporting, domestication or acculturation does not make the same meaning since in this case, "foreignisation is detrimental to understanding."

The aim of news translation is the dissemination of information, which is possible through complete comprehension by the target reader. Thus, retaining all foreign elements in target news stories will only hinder the understanding of the reader, and news circulation will not achieve its main goal, which is to inform the reader in various parts of the world. During this dissemination process, it is inevitable that some foreign elements are retained since globalization of information allows societies to become familiar with terms and expressions that are internationally recognized. However, domestication in news translation contributes to smooth understanding of the target reader.

The following passage is a clear example of domestication in which the Arabic target sentence seems accurate and 
communicative.

\section{e.g. Senate Votes to End Aid for Yemen Fight Over Khashoggi Killing and Saudis' War Aims}

(The NewYork Times, Dec 13, 2018)

مجلس الشيوخ يسدد ضربة موجعة لترامب بثأن اليمن فضلا عن متابعته لتصويت مجلس الثيوخ الامريكي على وقف دعم واشنطن للرياض وعن

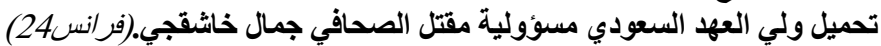

In fact, because of the journalistic discourse features, wether applying domestication or foreignization, it is better to use the literal translation of meaning in order to render the news faithful, efficient and successful.

e.g. Gunmen opened fire in a mosque in the city of Quebec on Sunday night, killing six people and wounding eight others in what Prime Minister Justin Trudeau called a "terrorist attack on Muslims.". (New York Times, 30/01/2017)

قتل ستة أشخاص وأصيب ثمانية آخرون عندما فتح مسلحون النار في مسجد في كيبيك أثناء صلاة العشاء، في اعتداء قال رئيس الوزراء الكندي

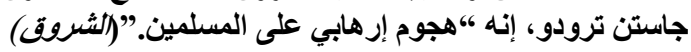

\subsubsection{Micro Strategies}

Transformations in the news texts during the translation process are carried out through such micro strategies as addition, omission, and substitution (Schäffner and Bassnett, 2010: 4). Moreover, making the obscure elements explicit, i.e. explication; adapting the foreign names to the spelling and pronunciation system of the target language, i.e.naturalization; and retaining foreign proper names, i.e. preservation are also observed during the transformation process of the news texts. Of these strategies, omission, addition, explication, substitution with cultural equivalents, and naturalization lead todomesticating translation, while preservation contributes to the foreign image of the texts.

\section{a. Omission}

This is the most adopted micro strategy in the production of target news texts. AsValdéon (2005) states, when omission is supported through clear contextual elements; they may not obstruct the reader'sunderstanding (p. 211). Omissions are performed due to several reasons, one of which is the space and time constraints. According to Valdéon (2005: 111), thanks to omissions, the trans-editor could transform the text in line with "the space requirements of the website."

However, another reason for omissions is highlighted: the irrelevant nature of the information for the target reader. The redundancy could stem from the lack of a source-cultural element in the target culture or from the distance of the region where the event takes place. AsXiaojuan (2010: 137) mentions, gaps between the source and target cultures necessitate the loss of information, which is also valid in the area of news translation.Irrelevant information is omitted in order to meet the particular needs of target readers (ibid., p. 140),

e.g.

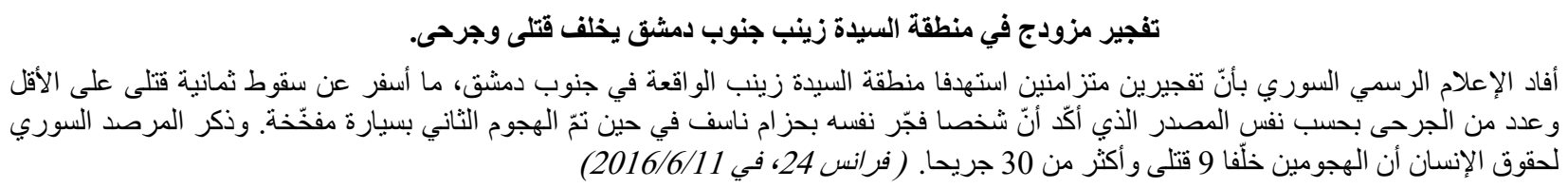

Fatalities in twin explosions near Damascus, Syria TV reports

Syrian State TV says two explosions have gone off near the Syrian capital, resulting in multiple casualties.(FRANCE 24 with AP, REUTERS.)

This passage forms the headline and the lead that precede the other information in the news text (the summary). The English summary (target text) seems shorter than the Arabic one (source text) since the translator/reporter has omitted some details which are not significant. It is simply synthesised, transmitting the essential news elements: what, when, where, who, why, how.

\section{b. Addition}

Addition is another micro strategy that is largely adopted in news translation. Additions are generally used since "news writers attempt to familiarize their readers with foreign institutions, norms, history or events" (Valdéon, 2008: 310) which may otherwise be foreign to "the reality surrounding the text consumer" (Valdéon, 2005b: 112).

Moreover, introductory additions are frequently inserted in target news texts. Valdeón (2005:113) gives an example regarding this situation. He states that in one of the source news texts, it is assumed that the reader is familiar with 
Bill Gates ("Bill Gates, the world's richest man.” = بيل غايت، أغنى رجل في العالم.); however, in the Spanish news, additional information regarding Bill Gates is supplemented ("BillGates, the founder of the Microsoft and the world's richest man.")

= (بيل غايت، مؤسس المايكروسوفت وأغنى رجل في العالم.)

Furthermore, details regarding specific events such as an opening ceremony, a meeting, or a summit including 'time, place, the course of events, the characteristics of objects and actors, the type and manner of action' (Vuorinen 1996: 210) could also be supplemented as additional information in target news texts. Thus, it could be suggested that such event-specific details as well as culture-specific additions and extensions of information introducing foreign institutions or historical elements are the major types of additions in news translation, which serve the function of enlightening the reader about the foreign events happening elsewhere in the world.

Here are some examples to clarify more this strategy;

e.g. Zika will burn out in three years ( BBC News) =

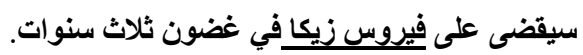

Donald Trump says 'rogue killers' may have murdered Khashoggi.

$$
\text { قال الرئيس الأميركى دونالد ترامب إن الصحفى السعودي جمال خاثقجي قد يكون قتل على أيدي "قتلة مارقين". (الجزيرة) }
$$

\section{c. Explication/Clarification}

Another strategy adapted to a large extent in news translation is news explication or clarification. According to Xiaojuan (2010), cultural gaps between the source text and the target text are brought closer through the explanations provided by trans-editors by means of 'adding further details within brackets or footnotes, or bytransplanting cultural aspects into the translation itself' (p. 137).

e.g. Iranian nuclear scientist defects to the US as CIA agent. =

$$
\text { انثقاق عالم نووي إيراني ليصبح عميلاً في وكالة المخابرات المركزية الامريكية. }
$$

\section{d. Substitution with Cultural Equivalents}

In Newmark's (1988: 82) terms, it refers to an "approximate translation where a SL cultural word is translated by a TL cultural word." Whereas, Sarra Bani (p.42) states that the cultural element is simply eliminated or synthesised when it is not considered significant inside the translated article. Therefore, she suggests cutting or summary as transfer techniques.

In fact, the journalistic discourse comprises a number of specific lexical units which denote such concepts that are characteristic of a certain nation and their linguistic view of the world. Most of these units are classified as culture-specific vocabulary or linguistic realities such as;

$\checkmark$ Socio-political institutions and organisations:CIA, FBI, NATO, Senate, ,..

$\checkmark$ Professional, gender, national and religious groups: Pope of Rome, DAECH,...

$\checkmark$ Habits, traditions, celebrations : kulich, five o'clock tea, Aïta, Halween, Hijab...

$\checkmark$ Units of measurement, currency units : inch, gallon, yen...

$\checkmark$ Names of administrative division: State, District, provence, wilaya...

$\checkmark$ Names of businesses : Apple, Huawei,...

Moreover, this strategy could be applied when transferring the political aspects and ideological concepts that distinguish the socio-politicallife of a community; as it is mentioned in the example below:

e.g. Donald Trump says 'rogue ${ }^{1}$ killers' may have murdered Khashoggi. (The Gardian, 16/10/2018)

${ }^{1}$ rogue (n): 1. An elephant or other large wild animal living apart from the herd and having savage or destructive tendencies. 2. A person or thing that behaves in an aberrant or unpredictable way, typically with damaging or dangerous effects. When something is described as "rogue", it normally implies it acts under its own volition, without constraint from some governing body or authority. 
In his speech, the American President, Trump, used the expression "rogue killer" which refers to someone who works alone and who kills in an unpredictable way or for obscure reasons. Trump calls Khashoggi's killers "rogue" to suggest they were not acting under any official orders (presumably from the Saudi royal family).Whereas, this expression is translated into Arabic context by عتلة مارقين and عناصر غير منضبطين which mean someone who turns against, changes his loyalty especially from a military organisation or political party. Therefore, the Arabic equivalent seems adequate.

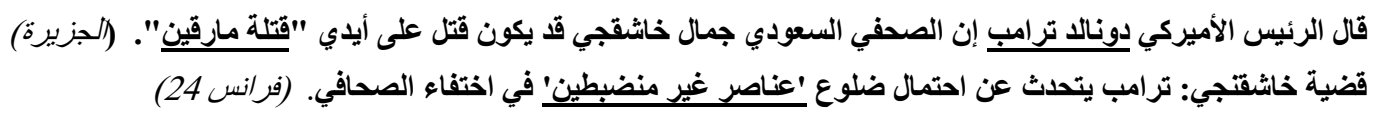

\section{e. Naturalization}

It is a strategy that adapts words to the phonological rules of the target language (Judickaite, 2009: 37). According to Newmark (1988: 82), naturalization "succeeds transference and adapts the SL word first to the normal pronunciation, then to the normal morphology of the TL." In the news texts, foreign names that might make the reading difficult and thus might hamper the comprehension process may be rewritten according the pronunciation and spelling rules of the target language. Simply, it is a sort of transliteration.

\section{e.g. Israel accuses Syria over Hezbollah missiles.=إسرائيل تتهم سوريا بتسليح حزب الله بالصواريخ}

\section{f. Preservation}

Preservation is to retain proper names such as names of local institution, journals, and applications or projects developed by institutions or centers during the translationprocess. This is a foreignizing strategy, and according to Pedersen (2005), it is the strategy that is the most oriented towards the source language (p. 116).It is used to keep the local colour. Indeed, when reporting news, journalist / translator needs to preserve some foreign elements since the news represents an event that happens abroad.

\section{e.g.Death toll from 'Volcano Tsunami' in Indonesia climbs to more than 370.}

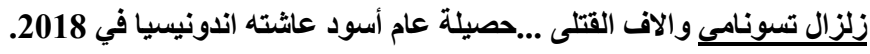

Consequently, there might be other micro strategies which contribute to the acculturation and recontextualisation in another culture; however, the methods mentioned above are the common one for ensuring a credible and efficient news translation.

And since the essential aim of news reporting is to inform readerson the current affairs throughout the world, the general tendency in news translation istowards creating a target-oriented tone, which is usually achieved throughdomestication strategies. Domesticating strategies, indeed, enable the target readers to understand the events worldwide from a familiar perspective.

\section{Conclusion}

To sum up, the journalistic translation contributes to the international news transmission. It plays a vital role in informing readers and shaping their opinions. However, translation should be culturally acceptable for the target audience. For this, the translator has to be aware of the social, political, cultural environment and the mechanisms of the media addressing the target audience.Therefore, he has to adopt some efficient news translation strategies, namely omissions, additions, explications, naturalizations, substitution that could achieve a domesticated journalistic discourse since the aim of these strategies is to make the news texts as comprehensible, fluent, and transparent as possible. In this regard, journalistic translation is viewed as "rewriting in a particular house style."

Accordingly, a good transfer is better assured by trans-editing and reproduction among other appropriate strategies of news translation required for the journalistic discourse.

\section{References}

Aljazeera Net. Retrieved from https://www.aljazeera.net/news/international/2018/10/15/\%D8\%AA\%D8\%B1\%D8\%A7\%D9\%85\%D8\%A8-\% D8\%AE\%D8\%A7\%D8\%B4\%D9\%82\%D8\%AC\%D9\%8A-\%D9\%82\%D8\%AF-\%D9\%8A\%D9\%83\%D9\%88 \%D9\%86-\%D9\%82\%D8\%AA\%D9\%84-\%D8\%B9\%D9\%84\%D9\%89-\%D9\%8A\%D8\%AF-\%D9\%85\%D8\%A 7\%D8\%B1\%D9\%82\%D9\%8A\%D9\%86

Bani, S. (2006). An Analysis of Press Translation Process. In K. Conway \& S. Bassnett (eds.), Translation in global news: Proceedings of the conference held at the University ofWarwick, 23 June 2006, 35-45. Retrieved from http://humanities.ufs.ac.za/dl/userfiles/Documents/00001/931_eng.pdf 
Bassnett, S. (2002). Translation Studies (3rd ed.). London and New York: Routledge.

Bassnett, S., \& Lefevere, A. (1992). General editor's preface. In A. Lefevere.Translation, Rewriting, and the Manipulation of Literary Fame. (pp. vii-viii).London and New York: Routledge. https://doi.org/10.4324/9780203427460

Bassnett. (2005). Bringing the News Back Home: Strategies of Acculturation andForeignisation. Language and Intercultural Communication, 5(2), 120-130. https://doi.org/10.1080/14708470508668888

Bielsa, E., \& Bassnett, S. (2009). Translation in Global News. London and New York: Routledge. https://doi.org/10.4324/9780203890011

Bielsa, E., \& Susan, B. (2009). Translation in Global News. London: Routledge, 2009. https://doi.org/10.4324/9780203890011

Bill, K. (2007). Translation and Journalism. The New York Times Blog, 2007. Retrieved from http://readingroom.blogs.nytimes.com/2007/10/31/translation-and-journalism/

Fowler, R. (1991). Language in the News: Discourse and Ideology in the Press, London and New York: Routledge.

France 24. Retrieved from http://www.france24.com/en/20160611-fatalities-twin-explosions-near-damascus-syria-tv-reports

Hatim, B., \& Mason, I. (1990). Discourse and the Translator. London and New York: Longman.

Miller, G. (1994). Toward Ethnographies of Institutional Discourse: Proposal and Suggestions. Journal of Contemporary Ethnography, 23(3), 280-306. https://doi.org/10.1177/089124194023003002

Newmark., P. (1988). A Textbook of Translation. NewYork: Prentice Hall Press.

Pym, A. (2008). Translation vs. Language Learning in International Institutions.Explaining the Diversity Paradox. Cultus, 1, 70-83. Retrieved from http://cultusjournal.com/1/upload/anthony_pym.pdf

Pym, A. (2010). Exploring Translation Theories. London and New York: Routledge. https://doi.org/10.4324/9780203869291

Salama-Carr (Ed.), Translating and Interpreting Conflict (Approaches to Translation Studies 28) (pp. 99-118). Amsterdam, New York: Rodopi.

Schäffner, C. (2009). Functionalist approaches. In M. Baker \& G. Saldanha (Eds.), Routledge Encyclopedia of Translation Studies (2 ed., pp. 115-121). London andNew York: Routledge.

Schäffner, C. (2012). Rethinking Transediting. Érudit Meta, 57(4), 866-883. https://doi.org/10.7202/1021222ar

Shuttleworth, M., \& Cowie, M. (1997). Dictionary of Translation Studies. Manchester, UK: St Jerome Publishing.

Stetting, K. (1989). Transediting: A new term for coping with the grey area between editing and translating. In G. Caie, K. Haastrup, A. L. Jakobsen, et al. (Eds.), Proceedings from the Fourth Nordic Conference for English Studies (pp.371-382). Copenhagen: University of Copenhagen.

The Guardian Newspaper. Retrived from https://www.theguardian.com/world/2018/oct/15/turkey-jamal-khashoggi-granted-permission-search-saudi-arab ia-consulate-istanbul

Valdéon, R. A. (2007a). Translating news from the inner circle: Imposing regularity across languages. Quaderns: Revista de Traducció, 14, 155-167.

Valdéon, R. A. (2007b). Ideological Independence or Negative Mediation: BBC Mundo and CNN en Español's (translated) Reporting of Madrid's Terrorist Attacks.

Valdéon, R. A. (2008). Anomalous news translation: Selective appropriation of themes and texts in the internet. Babel, 54(4), 299-326. https://doi.org/10.1075/babel.54.4.01val

Van Dijk, T. A. (1988a). News Analysis: Case Studies of International and NationalNews in the Press. Hillsdale, New Jersey: Lawrence Erlbaum Associates.

Van Dijk, T. A. (1988b). News as Discourse. Hillsdale, New Jersey: Lawrence ErlbaumAssociates.

Van Dijk, T. A. (1991). The interdisciplinary study of news as discourse. In K. Bruhn-Jensen \&N. Jankowksi (Eds.), Handbook of Qualitative Methods in Mass CommunicationResearch (pp. 108-120). London: Routledge.

Venuti, L. (1995). The Translator's Invisibility. London and New York: Routledge. 
https://doi.org/10.4324/9780203360064

Vermeer, H. J. (2000). Skopos and Commission in Translational Action (A. Chesterman,Trans.). In L. Venuti (Ed.), The Translation Studies Reader (pp. 221-232).London and New York: Routledge.

Xiaojuan, Q. (2010). Strategies for webpage trans-editing: A socio-cultural study. Working Ppaers of the Linguistic Circle of the University of Victoria, 20(1), 131-152. 